\title{
Electrical Submersible Pump Design in Vertical Oil Wells
}

\section{Abdelhady A, Gomaa S*, Ramzi H, Hisham H, Galal A and Abdelfattah A}

Petroleum Engineering and Gas Technology Department, Faculty of Engineering, The British University in Egypt, Egypt

*Corresponding author: Sayed Gomaa, Petroleum Engineering and Gas Technology Department, Faculty of Engineering, The British University in Egypt, El Sherouk City, Cairo, Egypt, Tel: 01115003694; Email: sayed.gomaa@bue.edu.eg

\section{Research Article}

Volume 4 Issue 5

Received Date: September 15, 2020

Published Date: October 16, 2020

DOI: $10.23880 /$ ppej-16000237

\section{Abstract}

Artificial Lift is a very essential tool to increase the oil production rate or lift the oil column in the wellbore up to the surface. Artificial lift is the key in case of bottom hole pressure is not sufficient to produce oil from the reservoir to the surface. So, a complete study is carried to select the suitable type of artificial lift according to the reservoir and wellbore conditions like water production, sand production, solution gas-oil ratio, and surface area available at the surface. Besides, the maintenance cost and volume of produced oil have an essential part in the selection of the type of artificial lift tool. Artificial lift tools have several types such as Sucker Rod Pump, Gas Lift, Hydraulic Pump, Progressive Cavity Pump, Jet Pump, and Electrical Submersible Pump. All these types require specific conditions for subsurface and surface parameters to apply in oil wells. This paper will study the Electrical Submersible Pump "ESP" which is considered one of the most familiar types of artificial lifts in the whole world. Electrical Submersible Pump "ESP" is the most widely used for huge oil volumes. In contrast, ESP has high maintenance and workover cost. Finally, this paper will discuss a case study for the Electrical Submersible pump "ESP" design in an oil well. This case study includes the entire well and reservoir properties involving fluid properties to be applied using Prosper software. The results of the design model will impact oil productivity and future performance of oil well.

Keywords: Submersible; Pump; Design; PROSPER; Artificial Lift; Oil Well

\section{Introduction}

Artificial lift is considered the backbone for enhancement productivity from oil wells in the world. Selecting the optimum artificial lift technique represents a challenge for the petroleum production engineer. Petroleum engineer could arrange the optimum type of artificial lifts according to technical and economical evaluation [1,2]. In addition, the reservoir drive mechanism has an important role in the selection of optimum type of artificial lifts. Therefore, in case of depletion drive mechanism with high initial oil rate in the early production life of reservoir, the optimum type of artificial lift is continuous gas lift or electrical submersible pump "ESP" could be applied. In contrast, with production time there are steep decrease in reservoir pressure, therefore the rate of produced fluid is decreased that requires to change the type of artificial lift tool to be intermittent gas lift or Sucker rod pump that run on oil wells having low productivity [3].

In case of bottom hole pressure is unable to lift fluids to the surface due to the reservoir pressure has been declined rapidly with excessive water production. Therefore, it is considered the optimum time to run artificial lift tools. These artificial lift tools could overcome the loss in reservoir pressure, which will help to increase drawdown due to reducing the bottomhole flowing pressure against sand face of the formation. The reduction in bottomhole flowing pressured leads to increase difference in pressure between reservoir and wellbore and increase in oil production rate as shown in Figure $1[4,5]$. 


\section{Petroleum \& Petrochemical Engineering Journal}

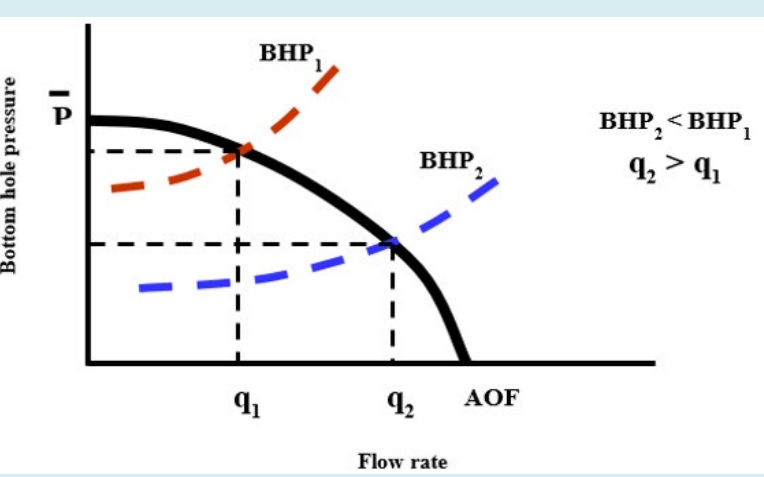

Figure 1: Well Deliverability before and after artificial lift.

There are different types of artificial lift tools with different specifications related to well parameters, reservoir and fluid properties. Each type of artificial lifts has different advantages and limitations according to its application on oil well. The artificial lifting tools include gas lift, Sucker Rod Pump, Hydraulic Pump, Progressive Cavity Pump and Electrical Submersible Pump [6-8]. There are many parameters affecting the selection of the optimum type of artificial lifting techniques that include reservoir, wellbore, surface and operation parameters.

The reservoir parameters are production rate, water production rate, solution gas oil ratio, oil viscosity, oil formation volume factor, inflow performance relationship, and the driving mechanism.

The surface conditions include location of field, power source, surface production rate, and contamination of fluids. The conditions of field operation are plan for pressure maintenance, plan for long life recovery, surface facility, and plan for enhanced oil recovery. The wellbore parameters include total depth of the well, type of completion in the well, tubing and casing diameter, and deviation of wellbore $[9,10]$.

\section{Operating Conditions for Artificial Lift tools}

Different Types of artificial lift tools have been applied on oil wells according to reservoir, wellbore and surface conditions that each type of artificial lifts has some conditions are favorable to apply in addition to the components of reservoir production as presented in Table 1[11].

\begin{tabular}{|c|c|c|c|c|}
\hline Operating Conditions & Rod Pump & Hydraulic Pump & Electric Submersible Pump & Gas Lift \\
\hline Sand & Fair & Fair & Fair & Excellent \\
\hline Paraffin & Poor & Good & Food & Poor \\
\hline High Gas oil ratio & Fair & Fair & Fair & Excellent \\
\hline Deviated Hole & Poor & Good & Fair & Good \\
\hline Corrosion & Good & Good & Excellent & Good \\
\hline High Volume & Poor & Good & Fair & Good \\
\hline Depth & Fair & Excellent & Poor & Good \\
\hline Flexibility & Fair & Excellent & Poor & Fair \\
\hline Scale & Good & Fair & &
\end{tabular}

Table 1: Comparison between all types of artificial lifts.

\section{Electrical Submersible Pump}

Electrical Submersible Pump is the most familiar and widely used in the petroleum industry in the world which more than 100000 oil wells are using electrical submersible pump in the world in order to lift the fluids to the surface or in order to accelerate the well production. This type of Pump is familiar in handling huge quantity of fluids to the surface even if high amount of water produced with oil. The major components of this type of pump is multistage centrifugal pump is attached to downhole motor by shaft. Heavy cable is delivered from the surface to downhole motor in order to deliver the electricity. In addition, there are downhole protector that could create an additional seal to the downhole motor in order for further protection as shown in Figure 2 $[12,13]$.

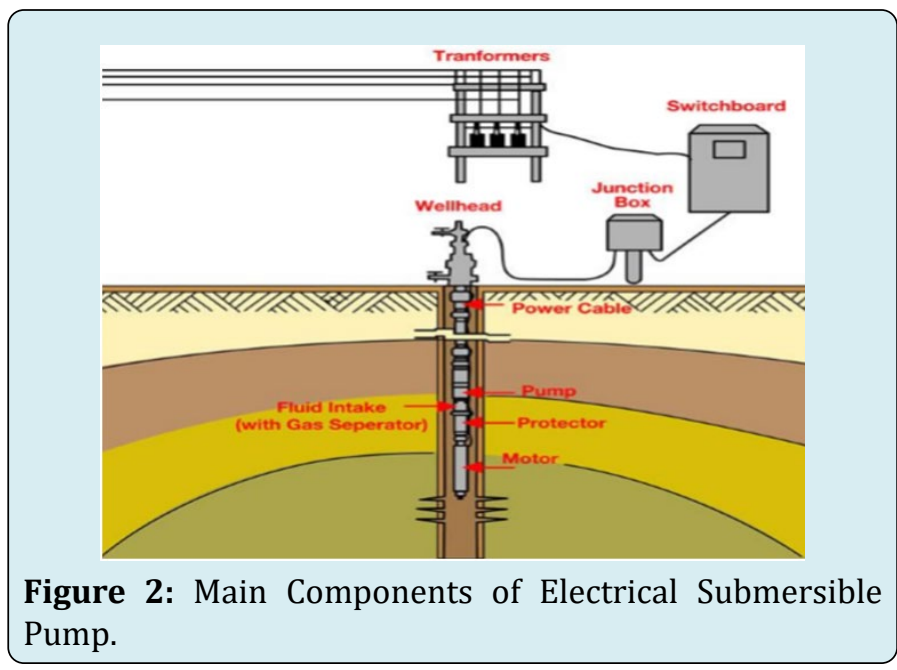

Copyright@ Gomaa S, et al. 


\section{Petroleum \& Petrochemical Engineering Journal}

\section{Advantages of Electrical Submersible Pump $[9,14]$}

1. Electrical Submersible Pump can provide large produced liquid volume from the reservoir

2. Electrical Submersible Pump has only limited equipment at the surface

3. Electrical Submersible Pump is highly recommended in highly deviated wells and in wells with severe dogleg.

4. Electrical Submersible Pump efficiency is very high that produce greater than $1000 \mathrm{bbl} /$ day liquid.

5. Electrical Submersible Pump has high resistance to corrosion in oil wells.

6. Electrical Submersible Pump has low cost of maintenance.

\section{Limitations of Electrical Submersible Pump $[9,15]$}

1. Electrical Submersible Pump has a great problem in case of sand production from reservoir to the wellbore.

2. Electrical Submersible Pump has a great problem in case of high gas oil ratio is produced from the reservoir or in case of high bottom hole pressure in some oil wells with great depth.

3. Electrical Submersible Pump is difficult to use in case of low oil production from some wells. In case of production is lower than 200 barrel per day.

4. Electrical Submersible Pump is very critical in case of oil wells in the offshore area.

5. Electrical Submersible Pump requires large diameter of casing in case of high volume of liquid produced from the reservoir.

6. Electrical Submersible Pump is very costly in case of there is a failure in the downhole motor.

There are several softwares designed to build a model for electrical submersible pump for any oil well according to several conditions. These conditions such as reservoir properties, well parameters and surface conditions could enable us to select the best and optimum Electrical Submersible Pump parameters that match all conditions in order to enhance well performance and increase well productivity. One of the main parameters is gas oil ratio that influence on number of stages in ESP pump. Increasing gas oil ratio that produced from the reservoir will increase number of stages in the pump. One of the most familiar and widely used software is PROSPER that could select the optimum design for electrical submersible pump for all oil wells conditions [16].

There are some constrains for electrical submersible pump such as sand production from reservoir to the wellbore. In these conditions, downhole screen or filter has to be installed against the formation intervals in order to prevent any wear in the downhole pump. So, most of wells that have sand production, also have gravel pack in order to protect downhole motor from sand. However, most of artificial lift tools could not handle sand production from reservoir to the wellbore. There are only two types of artificial lift tools could handle sand production. These two types are gas lift and progressive cavity pump [12].

\section{Design of Electrical Submersible Pump}

Table 2 presents the reservoir and fluid properties for an oil well is producing from black oil reservoir has low productivity due to losses in wellbore pressure from sand face to the surface. Therefore, it is planned to design Electrical submersible pump to maximize oil productivity from well. The reservoir has high oil potential and large oil volume could deliver to the well bore which requires an artificial lift tool to produce large volume of oil production to the surface. The benefit of Electrical submersible pump is producing large liquid volume because it has the ability to carry large quantity of liquid to the surface. Figure 3 displays the input fluid properties in order to match the reservoir data.

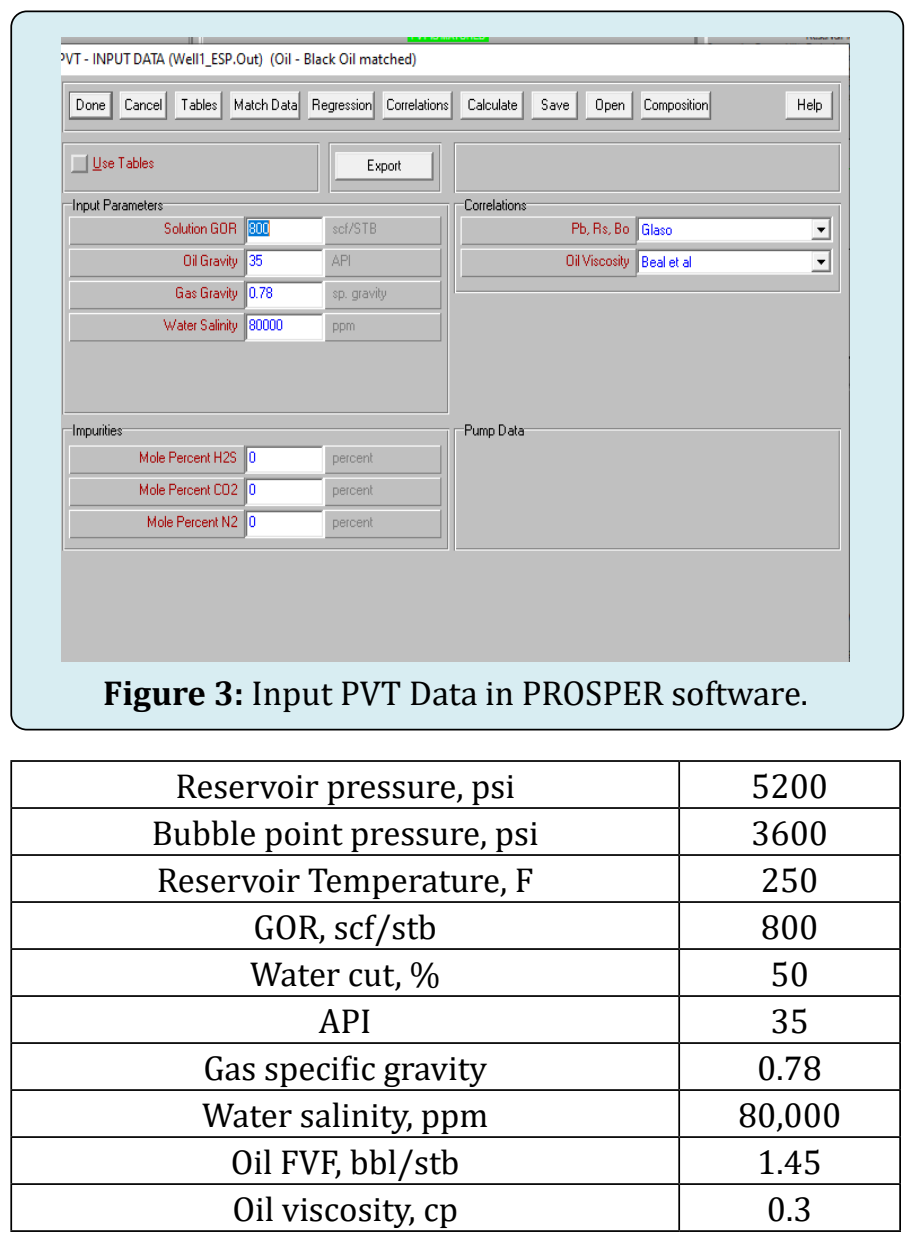

Table 2: Reservoir and fluid properties. 


\section{Petroleum \& Petrochemical Engineering Journal}

This PVT data have to be matched with the matching parameters using the suitable correlation in PROSPER model. There are several correlations could be applicable. Prosper software will make a lot of iterations in order to achieve the best correlation that will represent the reservoir fluid properties. Figure 4 depicts the matching parameters have to be matched with fluid properties.

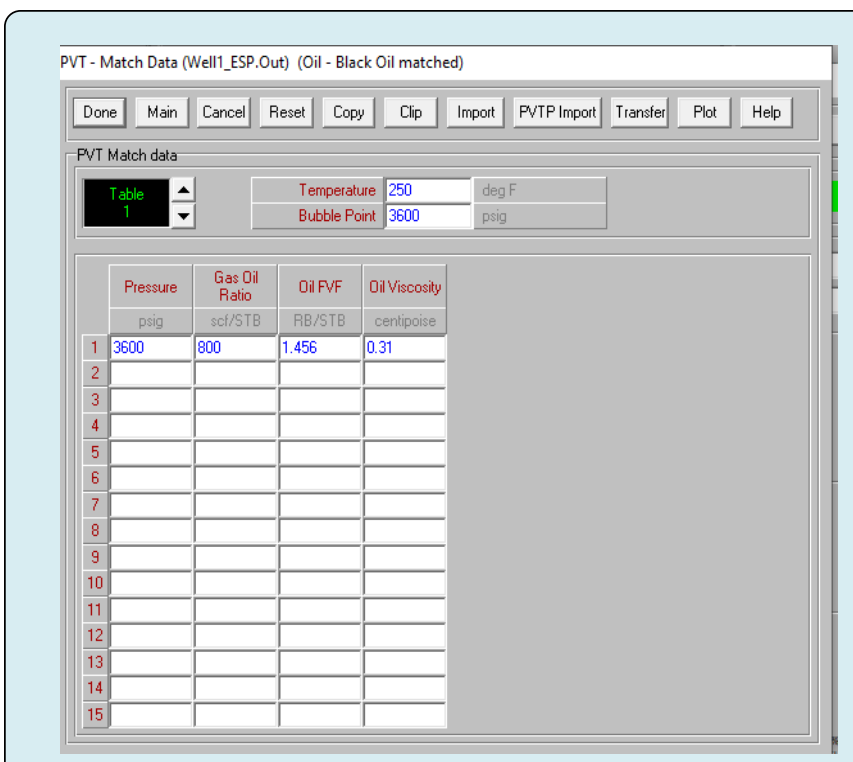

Figure 4: Matching parameters for fluid properties.

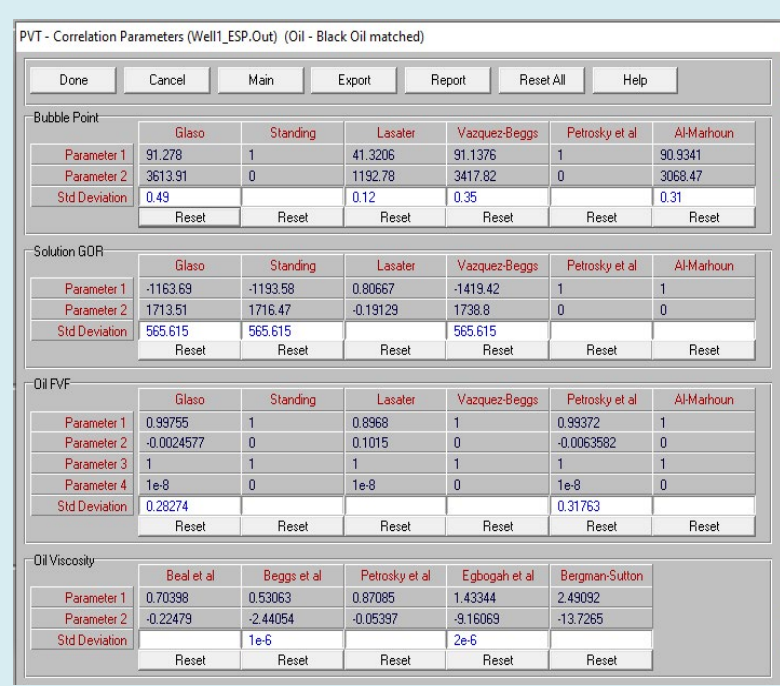

Figure 5: Different correlations selection for matching parameters.

The best correlation will be selected depending on two parameters. The first parameter must be closest to one in value while, the second parameter must be near to zero in order to achieve the lowest standard deviation. Figure 5 shows the different correlations used in PROSPER model.
The best correlation for calculating solution gas oil ratio, bubble point pressure and oil formation volume factor is Glaso correlation where, Beal et al. correlation is the best on for calculating the oil viscosity. These correlations will be applied to predict the future performance of reservoir fluid.

\section{Inflow Performance Relationship}

Inflow performance relationship "IPR" represents the performance of reservoir to deliver liquid to the wellbore. In order to establish the inflow performance relationship, it is required to import reservoir parameters depending on reservoir model selected such as reservoir pressure, reservoir temperature, water cut from reservoir, gas oil ratio and productivity index of reservoir. Then plot inflow performance of reservoir as shown in Figure 6.

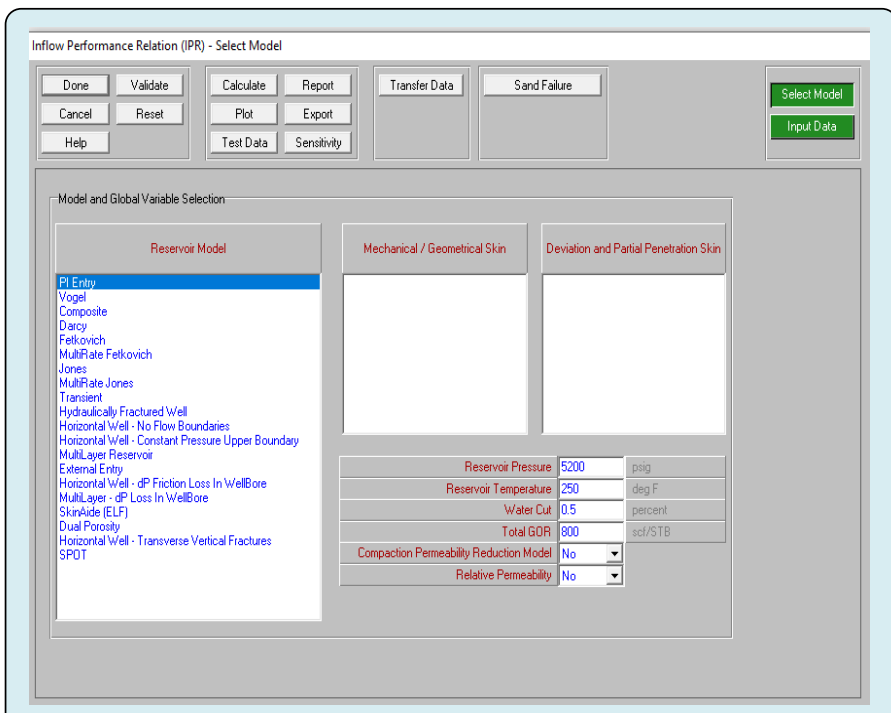

Figure 6: Model selection and required parameters for IPR.

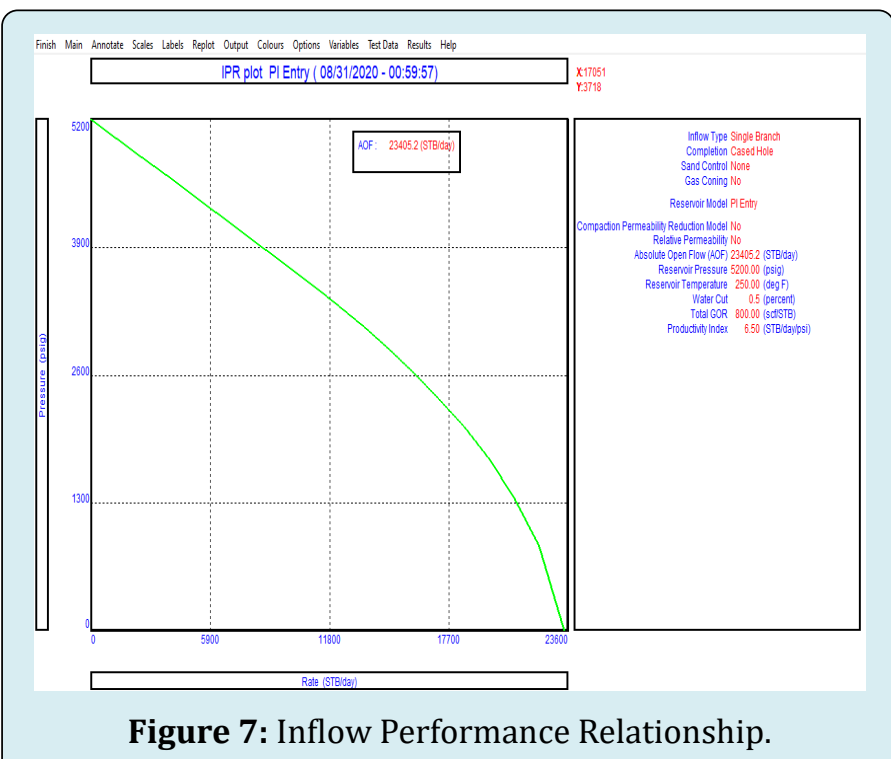




\section{Petroleum \& Petrochemical Engineering Journal}

PROSPER software will use the above reservoir parameters to calculate the inflow performance relationship at different pressure values then plot this inflow performance on curve that will be illustrated in Figure 7.

\section{Vertical Lift Performance Data}

There are several parameters will control the value of pressure losses in the well such as deviation survey which represents the change in well trajectory regarding to the vertical depth of the well. Figure 8 displays the input data for deviation survey on PROSPER model.

Downhole equipment represents the different sizes of each equipment in the well bore that may cause pressure loss due to the obstruction of different sizes in the well bore. Figure 9 shows the input equipment in this case study.

Geothermal Gradient represents the change in temperature with depth, as it will have an impact on the well productivity and well bore pressure. Figure 10 illustrates the input temperature change with depth in the wellbore.

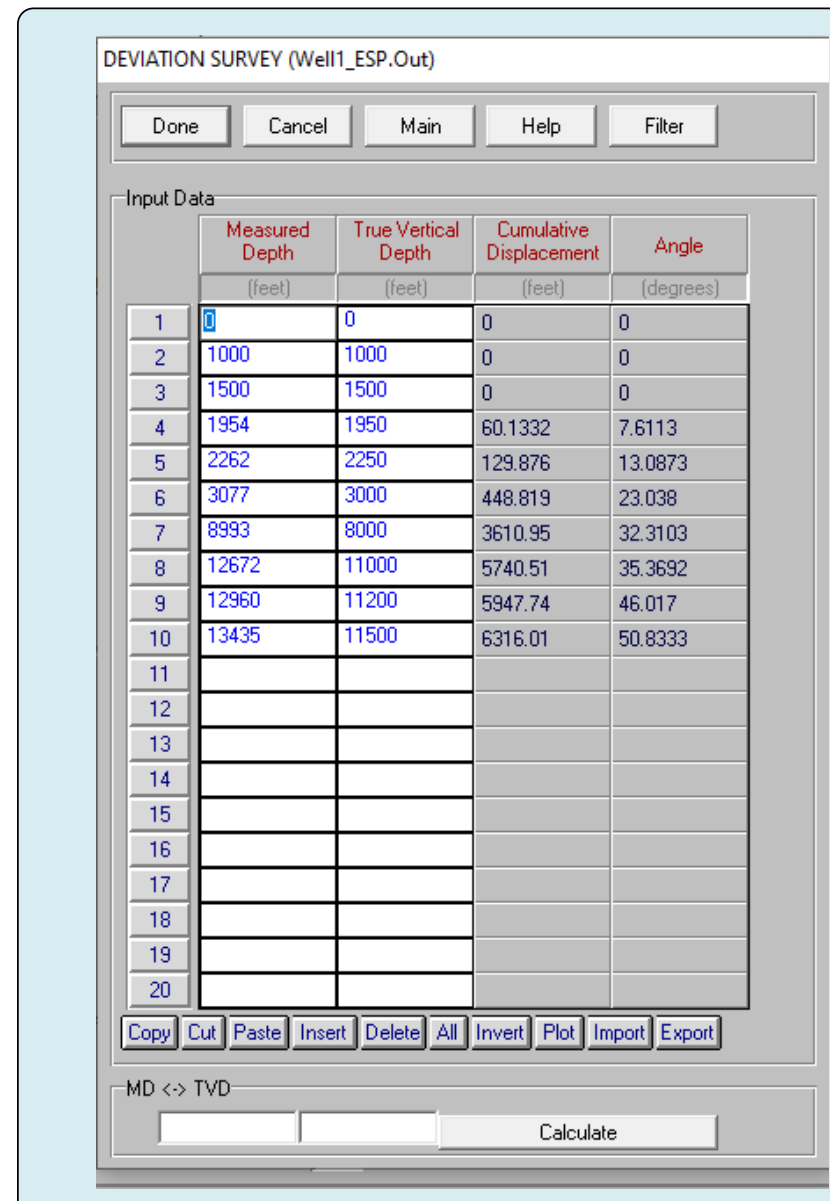

Figure 8: Well Deviation survey.

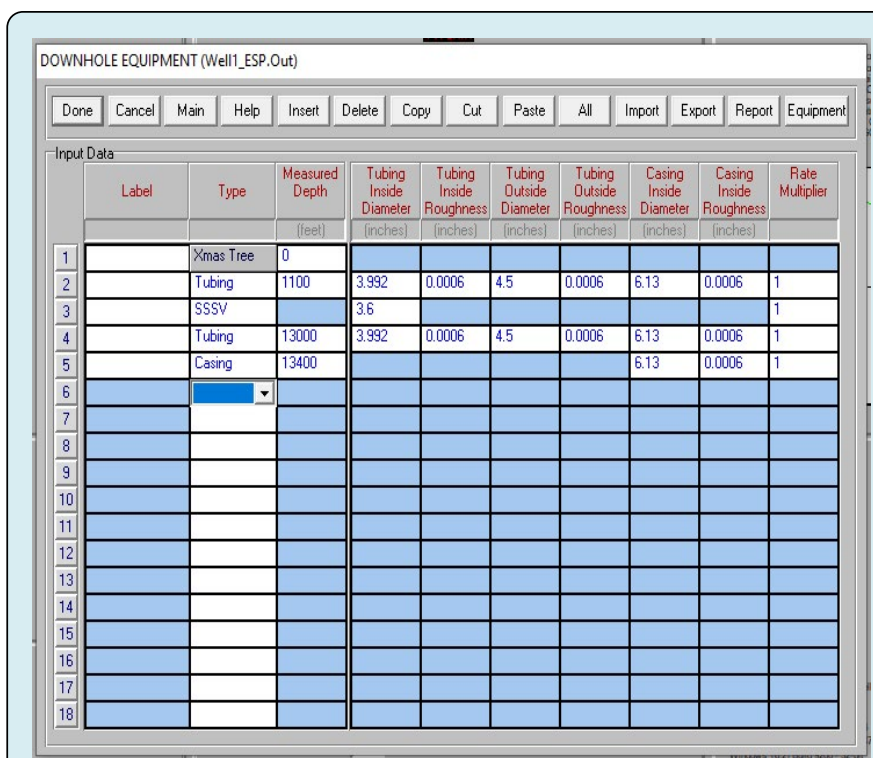

Figure 9: Well Downhole Equipment.

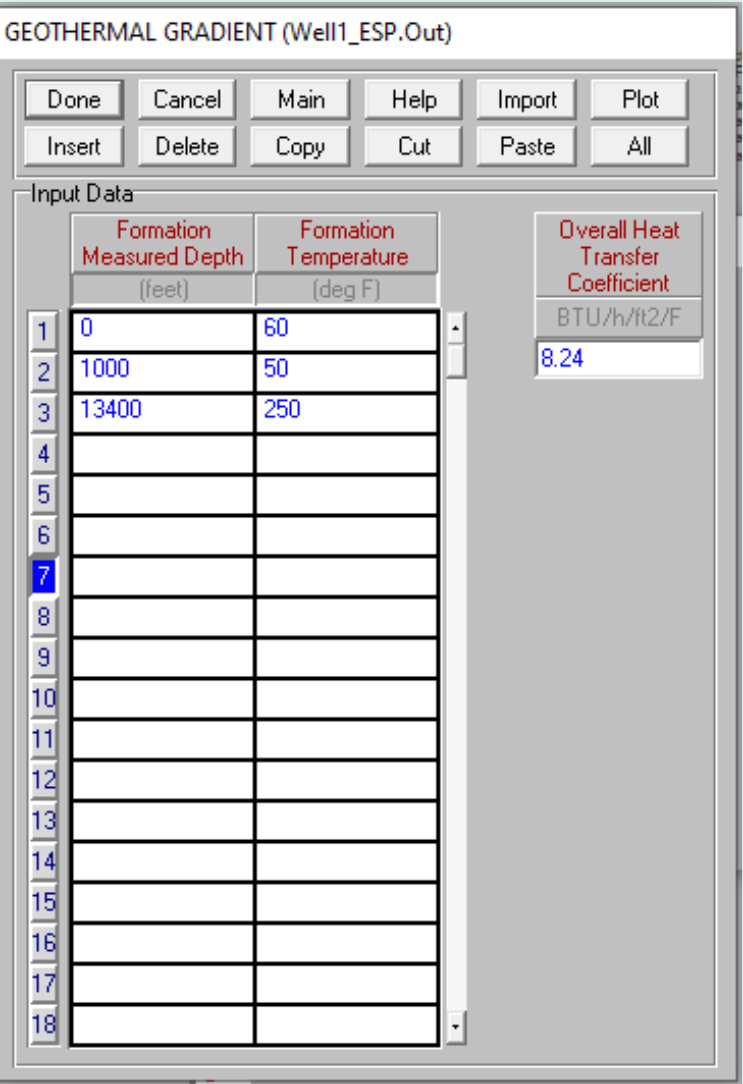

Figure 10: Well Geothermal Gradient.

After constructing the inflow performance relationship that represents the reservoir deliverability, the design of electrical submersible pump requires several input parameters in order to evaluate the efficiency of electrical 


\section{Petroleum \& Petrochemical Engineering Journal}

submersible pump and calculate the different outputs.

There are several input parameters are required to design electrical submersible pump. These parameters such as depth of pump, length of power cable, required rate, reservoir water cut, gas oil ratio of reservoir, top node pressure. The input parameters have been imported in PROSPER software as shown in Figure 11.

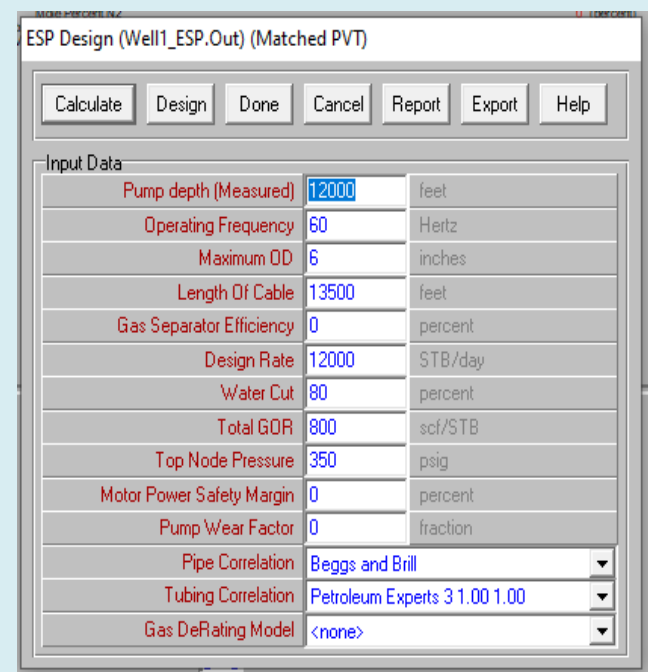

Figure 11: Data required for electrical submersible pump design.

\section{Results of Electrical Submersible Pump Design}

By using the input parameters, PROSPER software could calculate the pump intake pressure, pump discharge pressure, pump discharge rate, actual head required as shown in Figure 12.

\begin{tabular}{|c|c|c|c|c|c|c|}
\hline \multicolumn{7}{|c|}{ ESP Design (Well1_ESP.Out) (Matched PVT) } \\
\hline Done & Calculate & Main & Help & Export & Sensitivity & \\
\hline \multicolumn{2}{|c|}{$\begin{array}{l}\text { Flowing Bottomhole Pressure } \\
\text { Water Cut } \\
\text { Pump Frequency } \\
\text { Pump Intake Pressure } \\
\text { Pump Intake Temperature } \\
\text { Pump Intake Rate } \\
\text { Free GOR Entering Pump }\end{array}$} & $\begin{array}{l}3352.25 \\
80 \\
60 \\
2941.35 \\
249.012 \\
13787.6 \\
182.314\end{array}$ & $\begin{array}{l}\text { [psig) } \\
\text { (percent) } \\
\text { (Hertz) } \\
\text { (psig) } \\
\text { (deg) } \\
\text { (RB/day) } \\
\text { (sct/sTB] }\end{array}$ & & & $\wedge$ \\
\hline \multicolumn{2}{|c|}{ Pump Discharge Pressure } & 4510.68 & [psia] & & & \\
\hline \multicolumn{2}{|c|}{$\begin{array}{l}\text { Pump Dischage Rate } \\
\text { Total GOR Above Pump } \\
\text { Mass Flow Rate } \\
\text { Total Fluid Gravity } \\
\text { Average Downhole Rate } \\
\text { Head Required } \\
\text { Actual Head Required } \\
\text { Fluid Power Required } \\
\text { GLR At Pump Intake }(\mathrm{VN}) \\
\text { Gas Fraction At Pump Intake }\end{array}$} & $\begin{array}{l}13479.2 \\
800 \\
4378361 \\
0.91992 \\
13577.5 \\
3939.01 \\
3939.01 \\
361.757 \\
0.034798 \\
0.033627\end{array}$ & $\begin{array}{l}\text { (RB/day) } \\
\text { (scc/STB) } \\
\text { (bm/day) } \\
\text { (RB/day) } \\
\text { (feet) } \\
\text { (feet) } \\
\text { (hp) } \\
\text { (fraction) } \\
\text { (fraction) }\end{array}$ & & & $v$ \\
\hline
\end{tabular}

Figure 12: Calculations required to design the electrical submersible pump.
Finally, PROSPER could design the optimum parameters and output of electrical submersible pump that will be applied in this well. The results of PROSPER for electrical submersible pump design are number of pump stages equal 106 stage, required power equal $571 \mathrm{hp}$, the outlet temperature of the pump equal $255 \mathrm{~F}$ and the efficiency of electrical submersible pump equal $64 \%$. Figure 13 illustrates the results of electrical submersible pump design by PROSPER software for this well. The operating area of electrical submersible pump is shown in Figure 14.

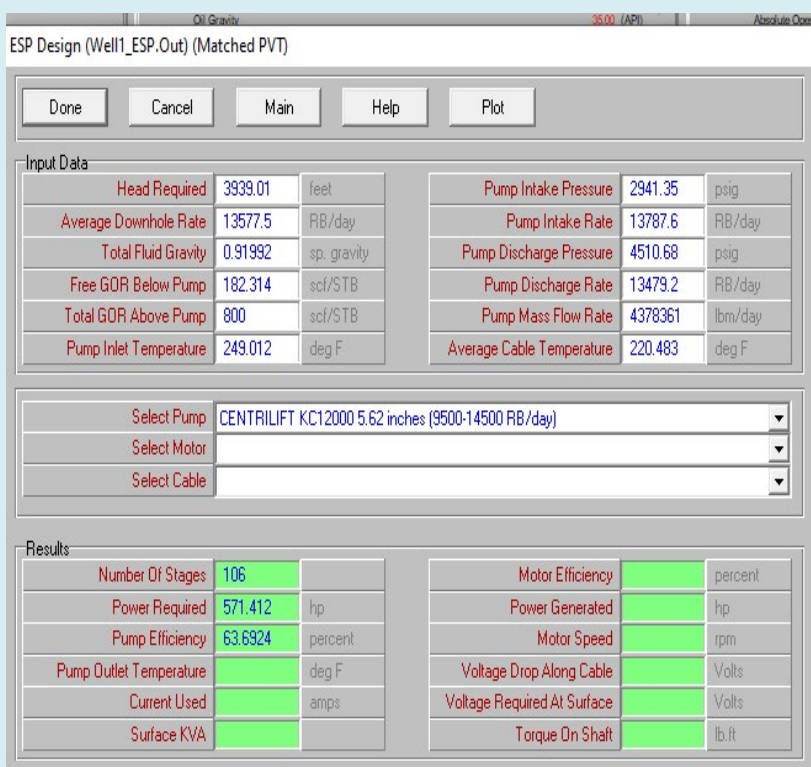

Figure 13: Results of the electrical submersible Pump Design.

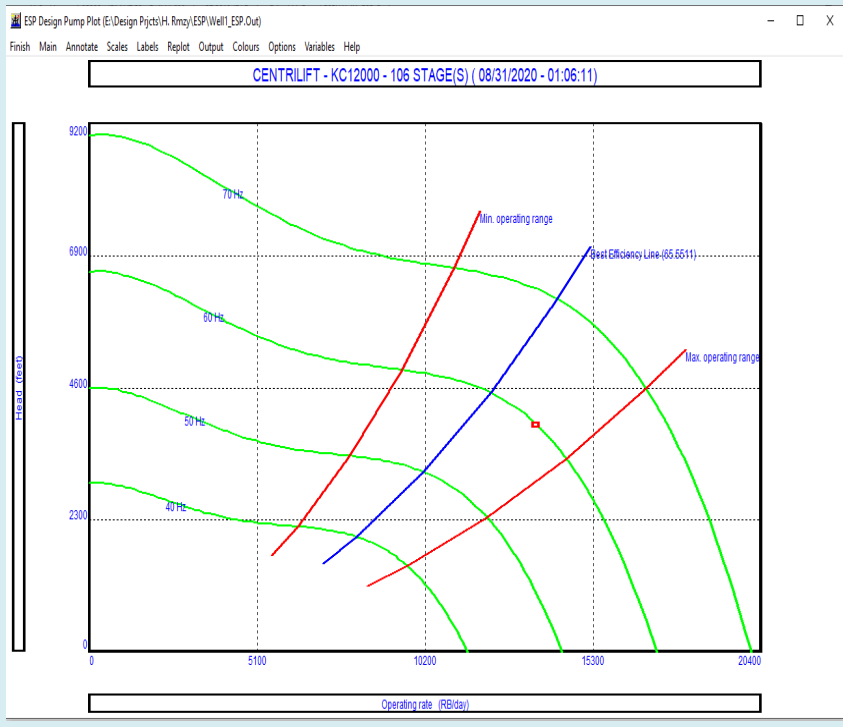

Figure 14: Electrical submersible pump Operating Area 


\section{Petroleum \& Petrochemical Engineering Journal}

\section{Conclusions}

An electrical submersible pump was designed for an oil well to enhance the well productivity and improve the well performance. The results of ESP design in Prosper software indicated the operating area of pump, the pump efficiency, and number of stages required to lift liquid volume to the surface. The results of PROSPER for electrical submersible pump design are number of pump stages equal 106 stage, required power equal $571 \mathrm{hp}$, the outlet temperature of the pump equal $255 \mathrm{~F}$ and the efficiency of electrical submersible pump equal $64 \%$.

\section{References}

1. Nguyen $T$ (2020) Artificial Lift Methods: Design, Practices, and Applications. $1^{\text {st }}$ (Edn.), Springer Nature, Germany, pp: 347.

2. Nguyen H, Del Mundo F (2016) Improving Artificial Lift Design Through Dynamic Simulation. SPE North America Artificial Lift Conference and Exhibition, Society of Petroleum Engineers, USA.

3. Brown KE (1982) Overview of Artificial Lift Systems. Journal of Petroleum Technology 34(10): 13.

4. Alemi M, Jalalifar H, Kamali G, Kalbasi M (2010) A prediction to the best artificial lift method selection on the basis of TOPSIS model. Journal of Petroleum and Gas Engineering 1(1): 9-15.

5. Brown KE (1977) Technology of artificial lift methods. Volume 1, Inflow performance, multiphase flow in pipes, the flowing well. US Department of Energy, Office of Scientific and Technical Information, United States.

6. James L (2007) Selection of Artificial Lift. SPE MidContinent Operations Symposium, Society of Petroleum Engineers, USA.

7. Takacs G (2015) Sucker-rod pumping handbook: production engineering fundamentals and long-stroke rod pumping. Gulf Professional Publishing, pp: 598.

8. Gilbertson E (2010) Gas lift valve failure mode analysis and the design of a thermally-actuated positive-locking safety valve. Massachusetts Institute of Technology, USA.

9. Takacs G (2017) Electrical submersible pumps manual: Design, operations, and maintenance. Gulf professional publishing, USA.

10. Bolovin EV, Glazyrin AS (2017) Method for identifying parameters of submersible induction motors of electrical submersible pump units for oil production. Bulletin of the Tomsk Polytechnic University, Geo Assets engineering 328(1): 123-131.

11. Lea JF, Nickens HV (2007) Selection of artificial life. Society of petroleum engineers, Oklahoma, USA.

12. Takacs G (2018) Electrical Submersible Pump Manuals. $2^{\text {nd }}(E d n$.$) , Gulf professional publishing, USA.$

13. Clegg JD (2007) Petroleum Engineering Handbook. Volume IV, Production Operations Engineering, Society of Petroleum Engineers, USA.

14. Zhu J, Banjar H, Xia Z, Zhang HQ (2016) CFD simulation and experimental study of oil viscosity effect on multistage electrical submersible pump (ESP) performance. Journal of Petroleum Science and Engineering 146: 735745 .

15. Pessoa R, Prado M (2003) Two-phase flow performance for electrical submersible pump stages. SPE production \& facilities 18(1): 13-27.

16. Chikwere E, Sylvester O, Appah D (2015) Economic evaluation of Electrical Submersible Pump (ESP) and gas lift well for production optimization in a Niger Delta Field. International Journal of Engineering and Technology 5(1): 56-68. 